\title{
Is it Important to Study Cultural Differences?
}

\author{
Jasna Kuljis ${ }^{1}$ and Patrick Halloran ${ }^{2}$ \\ ${ }^{1}$ People and Interactivity Research Centre, School of Information Systems, Computing and Mathematics, \\ Brunel University, West London, Uxbridge, United Kingdom \\ ${ }^{2}$ College of Computing and Information Science, Prince Sultan University, Saudi Arabia
}

\begin{abstract}
This paper discusses the authors' interest in effects of culture on website design in two cultures and on the evaluation of teaching in three cultures. We obviously thought the influence of culture important enough in these two very different contexts to warrant our consideration and investigation. In the case of website design, the intention was to discover any differences that can be attributed to cultural differences in order to inform website design when creating a website variant for a particular country or culture. In the case of evaluation of teaching, the intention was to investigate different approaches to evaluation of teaching in order to see whether there are any common themes emerging from the data. There are two slightly different outcomes. Both papers discover that culture does not play as important a role as initially thought. The paper investigating websites found some evidence of a collectivist culture. The paper on the evaluation of teaching, on the other hand, found the more important effect of institutional goals and objectives when conducting such evaluation than the country where such evaluation is conducted.
\end{abstract}

Keywords: cultural differences, website design, teaching, learning, evaluation of teaching

\section{Motivation}

What has been motivating us to study cultural differences? The answer to this question is not as straightforward as we initially thought. We used to think it obvious that our cultural heritage plays an important role in the way we think about the world and interpret the world, in the way we express ourselves and relate to others, and in relating to a particular set of values. We all have enough personal experience and remember situations when we were embarrassed by our inappropriate behaviour or reaction due to a misinterpretation of other cultures or when we were recipients of someone else's faux pas. Yes, there is enough anecdotal evidence to support claims that there are cultural differences. However, how prevalent and how important are these? Before answering this question we will provide some background to the two studies covered in this issue. The first study considers cultural differences in website design and the second one considers cultural differences in teaching students in three different cultures.

\section{Motivation for the Study of Website Design}

The study by Kim and Kuljis investigates possible manifestations of culture in website design. This study is based on the belief that the designers from two very different cultures such as the United Kingdom and South Korea would create appropriately different websites. The websites analysed were charity websites in the United Kingdom and in South Korea and they were all created primarily to appeal for donations from their citizens. We hence assumed that the designers would not be affected too much by the global website design trends and would adhere more to the local conventions. The reason why we wanted to establish whether there are any such conventions and what they are is to inform designers of websites how best to accommodate a particular country or culture. We thought this might be important in particular for companies that have a worldwide presence. Such companies usually offer variants of websites in several versions for different countries. How- 
ever, the variations usually stop short of any considerable design differences and entirely focus on the choice of language. Typically, these would be marketing websites, either commercial or tourist, e-commerce sites that try to reach wide markets, etc.

So, our study of charity websites from the United Kingdom and South Korea discovered many similarities in the way the websites are designed both in layout, use of colours and use of features. We uncovered some differences as well, and these might be attributed to culture. The main difference is the more common use of interactive features in South Korean sites, such as online communities (one third of all South Korean sites versus none in United Kingdom sites), which appear to be compulsory message boards in South Korean sites (all of considered South Korean websites and only one UK website). This phenomenon can be considered to reflect the 'collectivist' type of a society in accordance with the classification of South Korean culture (see Hofstede, 1980). Also, South Korean websites provide much more explicit details about donators and donations than the UK sites. This may be explained by its strong uncertainty avoidance culture such as in South Korea (see Hofstede, 1980) where individuals try to avoid ambiguous situations and are looking for what others did to possibly guide their own behaviour.

The observed differences may or may not be important. There might be other explanation for these differences such as the effect of technology infrastructure. South Korea used to have much higher broadband penetration rate than the UK. What is very interesting is how little otherwise the websites from South Korea and the UK differ. There might be a much stronger influence of the international conventions and standards for designing websites than that of local culture. Hence we may witness a convergence towards a common global standard in website design.

\section{Motivation for the Study of Evaluation of Teaching}

This study investigates how teaching is evaluated in three higher education institutions in three countries/cultures: a public university in
Australia, a private international university in Malaysia, and a private university in Saudi Arabia. The main motivation for this study was to ascertain how students in these three very different cultural settings respond to innovative teaching methods and how it affects their learning, by analysing three sources of evaluation data: summative feedback gathered through university driven student evaluation of teaching surveys; course-based formative student feedback; and peer-teacher observation. It is interesting that the three universities, even though based in different countries, following different educational systems, and having different goals, have surprisingly similar ways of collating students' evaluation of teaching as well as peer observations. Despite the inevitably different questions in administered surveys, each university basically aimed to assess the same things. The peer evaluation instruments were similar in recognising the nature of observation although varying slightly across the countries. The same teacher, who was employed in all three universities at one point in time, used the same formative course evaluation in all three universities. Obviously, these evaluations were not carried out simultaneously or in the same year. Therefore, some of the results might be influenced by the change in trends and emphasis as to what was important to the university in the study at that particular time. However, the overall results suggest that the influence, if there was any, was very slight.

What appears to be an important factor for positive student feedback and their success in the course was the motivation and personality of their teacher. This is neither new nor surprising. We all have similar experiences when a particularly good teacher inspired our interest and passion for a subject whereas a particularly bad teacher killed our interest for a subject for good. What is also not surprising is low confidence in the quality of university collated evaluation data. Low quality of data is attributed to the poorly communicated message to staff and students of the purpose for which the data is collated. It is interesting that even though the paper set to consider processes in university settings in three different cultures, there was no attempt to assess any differences that stem from the culture and none was consequently observed. All differences were attributed solely to 
the fact that institutions do a poor job of communicating their goals and aligning the objectives of quality to teaching with a proper incentive and reward schemes.

\section{Conclusions}

So, what can we say in general about the influence of culture? It would be thoughtless and arrogant to deny it just because it is very hard to capture manifestations and effects of culture. Is it important to study such effects? Our answer is: yes it is. However, this does not mean we should stop doing what we are doing just because at the moment we do not have sufficient knowledge of all relevant issues related to cultures to take into consideration. So, we should persevere in enriching our knowledge of our cultural differences because we can bridge them only if we are aware of them. But, maybe we should stop assuming that cultural differences are always significant or that they always matter.

\section{References}

[1] G. Hofstede, Culture's consequences: International differences in work-related values. Beverly Hills, CA, Sage, 1980.
Contact addresses:

Jasna Kuljis

People and Interactivity Research Centre School of Information Systems, Computing and Mathematics Brunel University

West London, Uxbridge Middlesex UB8 3PH United Kingdom e-mail: Jasna.Kuljis@brunel.ac.uk

Patrick Halloran College of Computing and Information Science Prince Sultan University Saudi Arabia e-mail: phalloran@cis.psu.edu.sa

JASNA KULJIS is a Professor and Head of Department of Information Systems and Computing (DISC) at Brunel University, London, UK. Her research interests in HCI include simulation modelling and healthcare applications, and she has published widely in the HCI and Operational Research literature. Jasna is also Director of the Brunel University Research Centre called People and Interactivity (PANDI). Jasna first attended the second ITI conference in 1980 (the conference was then called International Symposium Computer at University) with a paper in Croatian (it was then a choice between Croatian and English): Kuljis, J. and M.A. Vouk. Comparative analysis of some routines for numerical integration of the Fermi integral. She has attended most of the ITI conferences since then - in total more than 20 conferences. Since 2004 she has been a conference vice-chair for the topic Human Computer Interaction.

DR PATRICK HALLORAN is Assistant Professor of Information Systems at the College of Computing and Information Science at Prince Sultan University Saudi Arabia. His research interests are in software quality and process improvement, teaching and learning in higher education, and ICT human capital in developing countries. 
